\title{
Veinte peruanos del siglo XX
}

Manuel González Prada - Francisco García Calderón - Víctor Andrés Belaunde

José de la Riva-Agüero y Osma - César Vallejo - Honorio Delgado

José Luis Bustamante y Rivero - Pedro G. Beltrán - José Carlos Mariátegui

Víctor Raúl Haya de la Torre - Raúl Porras Barrenechea

Luis Alberto Sánchez - Jorge Basadre - José María Arguedas

Fernando Belaunde Terry - Luis Bedoya Reyes - Fernando de Szyszlo

Blanca Varela - Luis Banchero Rossi - Mario Vargas Llosa

Pedro Cateriano Bellido (Compilador)

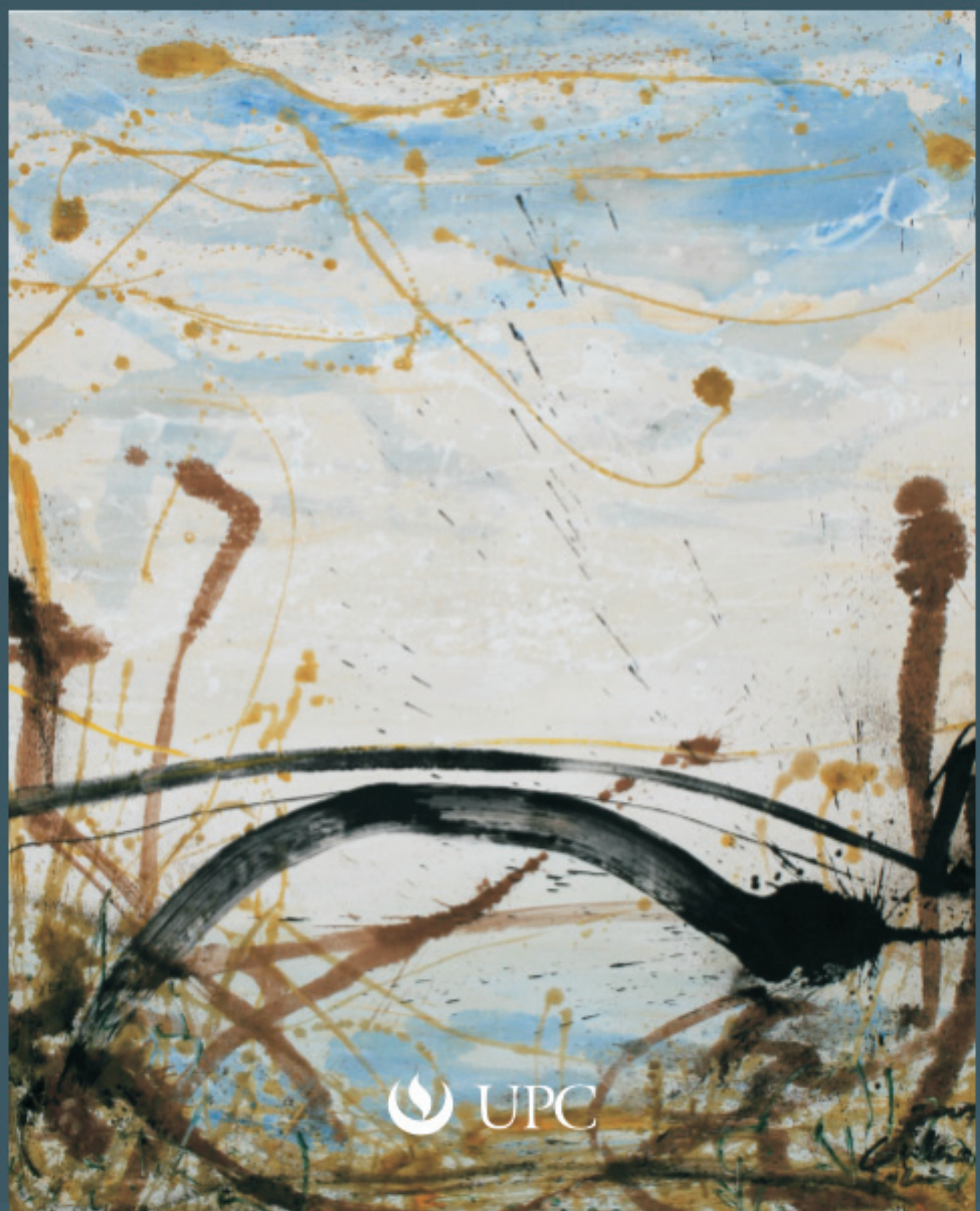




\section{Veinte peruanos del siglo XX}

Manuel González Prada - Francisco García Calderón - Víctor Andrés Belaunde

José de la Riva-Agüero y Osma - César Vallejo - Honorio Delgado

José Luis Bustamante y Rivero - Pedro G. Beltrán - José Carlos Mariátegui

Víctor Raúl Haya de la Torre - Raúl Porras Barrenechea

Luis Alberto Sánchez - Jorge Basadre - José María Arguedas

Fernando Belaunde Terry - Luis Bedoya Reyes - Fernando de Szyszlo

Blanca Varela - Luis Banchero Rossi - Mario Vargas Llosa

Pedro Cateriano Bellido (Compilador)

Lima, diciembre de 2010

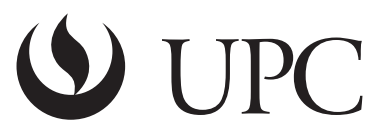


Compilador: Pedro Cateriano Bellido

(C) Universidad Peruana de Ciencias Aplicadas (UPC)

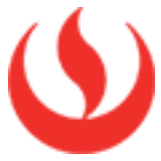

Primera edición: diciembre de 2010

Cubierta:

Guillermo Palacios Pomareda

Corrección de estilo:

Jorge Coaguila

Diseño de cubierta:

Giuliana Abucci

Diagramación:

Roxana Ishii

Fotografías:

Vicente de Szyszlo (álbum familiar)

(C) Universidad Peruana de Ciencias Aplicadas SAC

Av. Alonso de Molina 1611, Lima 33, Perú

Telef. 313-3333

http://www.upc.edu.pe

Digitalizado y Distribuido por YoPublico S.A.C.

\section{Dyopublico}

www.yopublico.net

Telf: 51-1-221 9998

Dirección: Av. 2 de Mayo 534

Of. 304, Miraflores Lima-Perú

\section{Universidad Peruana de Ciencias Aplicadas (UPC) \\ Centro de Información}

Pedro Cateriano Bellido (compilador). Veinte peruanos del siglo XX

Lima: Universidad Peruana de Ciencias Aplicadas (UPC), 2015

ISBN de la versión impresa: 978-603-4019-90-4

ISBN de la versión PDF: 978-612-4041-59-4

ISBN de la versión e-Pub: 978-612-4191-52-7

BIOGRAFÍAS, INTELECTUALES, POLÍTICOS, PRESIDENTES, LITERATOS, MÉDICOS, PINTORES, EMPRESARIOS, PERÚ

920.085 CHAN

Todos los derechos reservados. Esta publicación no puede ser reproducida, ni en todo ni en parte, ni registrada en o transmitida por un sistema de recuperación de información, en ninguna forma ni por ningún medio, sea mecánico, fotoquímico, electrónico, magnético, electroóptico, por fotocopia o cualquier otro, sin el permiso previo, por escrito, de la editorial.

El contenido de este libro es responsabilidad de los autores y no refleja necesariamente la opinión de los editores. 
Serie Puente Villena

Técnica mixta $185 \times 150 \mathrm{~cm}$

La Universidad Peruana de Ciencias Aplicadas (UPC) agradece a Guillermo Palacios Pomareda la cesión de su cuadro reproducido en la cubierta. 
Manuel González Prada (1844-1918)

Eugenio Chang-Rodríguez

Francisco García Calderón (1883-1953)

Osmar Gonzales Alvarado

Víctor Andrés Belaunde (1883-1966)

Diego García-Sayán

José DE LA Riva-AgÜERo y Osma (1885-1944)

José Agustín de la Puente Candamo

CÉsAr VAllejo (1892-1938)

Liliana Checa

Honorio Delgado (1892-1969)

Renato D. Alarcón-Guzmán

José Luis Bustamante y Rivero (1894-1989)

José Luis Sardón

Pedro G. Beltrán (1894-1979)

Arturo Salazar Larraín

José Carlos Mariátegui (1894-1930)

Iván Alonso

Víctor Raúl Haya de la Torre (1895-1979)

Carlos Espá

Raúl Porras Barrenechea (1897-1960)

Carlota Casalino Sen 
Luis Alberto SÁnchez (1900-1994)

Ismael Pinto Vargas

Jorge BASAdRE (1903-1980)

Rocío Chirinos Montalbetti

José María Arguedas (1911-1969)

Santiago Pedraglio

Fernando Belaunde Terry (1912-2002)

Miguel Cruchaga

Luis Bedoya Reyes (1919- )

Lourdes Flores Nano

Fernando DE SZYSZLo (1925- )

Mariella Balbi

Blanca Varela (1926- )

Giovanna Pollarolo

Luis BANCHERo Rossi (1929-1972)

Daniel Córdova Cayo

Mario Vargas Llosa (1936- )

Pedro Cateriano Bellido

RESEÑAS DE LOS AUTORES DE LOS TEXTOS 


\section{Presentación}

Destacar, entre otros, resulta condición indispensable para que la historia y los diccionarios reconozcan la definición de personaje.

Referirse a un personaje exige considerar la personalidad como un elemento básico e imprescindible. Plantea reconocer el conjunto de características y diferencias individuales que nos distinguen de otros, volviéndonos particulares e inconfundibles.

Estos ensayos no cuentan historias. Presentan formas de hacer historia.

Uno puede tener el deseo de convertirse en un personaje de la historia. No obstante, el mérito reside, justamente, en lograr que sean los otros los que encuentren en uno a un personaje con historia; a un personaje de la historia.

Este libro es una oportunidad para que veinte autores peruanos de diferentes generaciones y diversas ideologías, puntualmente seleccionados, acerquen a los lectores a veinte peruanos que durante el siglo XX evidenciaron una destacada participación en el pensamiento político, en la economía y en la cultura nacional del Perú.

Se trata, qué duda cabe, de un número arbitrario que por la exigencia de ser finito, explica su selección en función de su relación con el siglo que acabamos de finalizar, y cuya estela sigue siendo parte de nuestro océano.

Estamos conscientes de que el siglo nos ha dado muchos nombres adicionales; que le debemos una momentánea explicación a todas aquellas valiosas personas que colaboraron, desde sus quehaceres, con el desarrollo moral, político, económico y cultural del país.

Sin embargo, es indispensable que se comprenda que la selección de los personajes que presentamos, realizada al interior de la Universidad, se ha basado, fundamentalmente, en evidencias de biografías edificantes; en ideas que han guiado y marcado la historia del país, así como en el gran reconocimiento nacional e internacional labrado durante sus vidas.

Los autores de los textos, por su parte, son versados en la materia tratada y, en varios casos, han conocido, estudiado o trabajado directamente con los personajes centrales del libro. Ello convierte a cada uno de los ensayos en textos con personalidad y responsabilidad propias. 
Estos ensayos tienen, además, la profunda virtud de presentarnos personajes del siglo XX mientras, simultáneamente, describen y presentan a los autores. Cada ensayo nos muestra, sin habérselo planteado siquiera, la jerarquización, las huellas y la postura de sus autores. No cabe duda que se trata de un libro que invitará al debate.

Para la construcción y redacción de los textos, los autores han gozado de la mayor libertad de creación, llegando inclusive, en algunos casos, a esbozar apreciaciones o calificaciones personalísimas.

La idea es que a través de estos textos, cortos y de ágil lectura, los jóvenes conozcan a estos veinte grandes peruanos, y que su rica y variada trayectoria los ayude a comprender significativos sucesos acontecidos y sentidos en el Perú a lo largo del siglo XX.

El Fondo Editorial de la UPC quiere agradecer muy sinceramente al doctor Pedro Cateriano Bellido, compilador de esta obra, quien tuvo a bien compartir su proyecto con nosotros y trabajarlo, palmo a palmo, con cada uno de los autores. Sin su dedicación y cariño por recordar lo edificante y constructivo de los personajes seleccionados, este libro no habría sido posible.

A los autores de cada ensayo nuestro más sincero agradecimiento por haber aceptado el encargo con profesionalismo e indescriptible competencia.

Del mismo modo, la UPC quiere y debe dejar constancia de su agradecimiento a REPSOL YPF del Perú, empresa que con su contribución ha hecho posible la edición de este libro.

Lima, diciembre de 2008

Úrsula Freundt-Thurne Freundt

Directora del Fondo Editorial de la Universidad Peruana de Ciencias Aplicadas (UPC) 
Manuel González Prada

(1844-1918)

Eugenio Chang-Rodríguez 


\section{UNA VIDA EJEMPLAR}

Manuel González Prada, el más egregio pensador progresista peruano de fines del siglo XIX y principios del siglo XX, tiene un lugar prominente en la historia literaria latinoamericana. Sus escritos nutrieron e inspiraron a varias generaciones de sus discípulos deseosos de democratizar y modernizar el Perú. Nació en Lima este tercer vástago de Francisco González de Prada y Marrón de Lombera (1815-1863) y Josefa (Pepa) de Ulloa y Rodríguez de la Rosa (1820-1887), ambos de destacadas familias aristocráticas y religiosas. Manuel recibió la educación básica en Valparaíso y en Lima en el Seminario de Santo Toribio y en el Convictorio de San Carlos, plantel que ofrecía estudios secundarios y universitarios. En vez de concentrarse en los libros de texto, prefirió dedicarse a escribir versos y a leer obras literarias y discursos de congresistas liberales. A los dieciocho años de edad ya había compuestos algunos centenares de versos que no publicó ni compartió con nadie. Ganado por el interés literario, desechó el consejo paterno de recibirse de abogado, aunque aprobó todos los cursos de esa carrera y se retiró del convictorio sin obtener ningún grado universitario.

Hacia 1870 el joven Manuel se estableció en Tutumo, una de las propiedades familiares en el valle de Mala, provincia de Cañete, al sur de Lima, vecina a los contrafuertes andinos. Retirado en esa finca campestre, continuó leyendo a los clásicos de la lengua castellana, especialmente a Quevedo, Góngora, Fray Luis de Granada, los Argensola, Gracián, Cervantes y el Inca Garcilaso de la Vega, además de seguir familiarizándose con las obras de Goethe, Heine y otros grandes escritores alemanes. A veces interrumpía sus lecturas para estudiar química y realizar experimentos conformes con su proyecto industrial para obtener almidón y otros derivados de la yuca cultivada en sus tierras de Mala.

Pronto se le reconoció como poeta destacado, particularmente después de ser incluido en el Parnaso peruano, antología editada por José Domingo Cortés en Valparaíso, en 1871. El inquieto escritor publicaba poco: una que otra colaboración en El Correo del Perú y lo demás iba al canasto de papeles, después de seleccionar para sus archivos baladas indígenas como «Supay», «Huatanay», «La invención de la quena», «La aparición del coraquenque», «Caridad de Velarde», «La llegada de Pizarro» y otras composiciones 
publicadas póstumamente por su hijo Alfredo y Luis Alberto Sánchez. Sus observaciones del sufrimiento de la población nativa, conversaciones con los pongos y yanaconas le proporcionaron material para componer las baladas que publicó de 1871 a 1873 en El Correo del Perú y las incluidas póstumamente en Baladas peruanas, como «El mitayo» y «Las tres flechas del inca».

\section{DE ROMÁNTICO A PRECURSOR DEL MODERNISMO}

Aunque a los dieciocho años de edad Manuel ya había compuesto algunos centenares de versos, en su mayoría románticos, poco a poco se fue inclinando hacia la renovación literaria conocida después como modernismo. Por esos años también compuso algunas piezas teatrales. De 1866 a 1867 había terminado por lo menos el drama romántico Amor y pobreza y el sainete en verso festivo «La tía y la sobrina». No contento con su propia producción escrita, se dedicó a traducir al castellano poemas alemanes. El 18 de setiembre de 1867, el diario limeño El Comercio publicó su primera letrilla, firmada escuetamente «Manuel G. P.», sin el aristocrático «de» usado por la familia González de Prada. Así, el rebelde Manuel abdicaba a su alto rango social. Hizo lo mismo al publicar siete poemas sentimentales en el Parnaso peruano.

Don Manuel fue admitido como socio de la Sección Artes y Letras del Círculo Literario, presidido por Francisco García Calderón, futuro presidente del país. A esa prestigiosa organización pertenecían Ricardo Palma, Luis Benjamín Cisneros y otros distinguidos escritores civilistas. Pese a su vinculación con instituciones prestigiosas, el joven escritor continuó manifestando rebeldía contra las tradiciones aristocráticas, plutocráticas, religiosas y políticas, que eventualmente desembocó en una actitud radical, afín a la de Francisco de Paula González Vigil (1792-1875), sobre quien don Manuel escribió un ensayo biográfico en 1890, identificándolo como «solitaria columna de mármol a orillas de un río cenagoso».

\section{DOS AMORES Y UN MATRIMONIO ANTES DE LA GUERRA Del PaCÍfico}

En una de sus ocasionales visitas a Lima, don Manuel se enamoró de Verónica Calvet de Bolívar, de unos veinticinco años de edad, cuando don Manuel frisaba los treinta. De sus vínculos amorosos nació Mercedes, en 1878. ¿Por qué no se casaron? Tal vez porque el año anterior Manuel había conocido a Adriana de Vernehuil y Conches, agraciada adolescente francesa, con quien se casaría en 1887 y desde entonces se convertiría en la «animadora» de su esposo.

En 1880, cuando los chilenos triunfantes se acercaban a Lima, don Manuel combatió defendiendo el cerro del Pino (a unos dos kilómetros al sur de Lima), vecino a Chorrillos, donde los invasores dos días antes habían prendido fuego a la ciudad. Después de cum- 
plir el deber de defender a la patria, el entristecido Manuel se encerró en la casa materna durante la mayor parte del cuatrienio de la ocupación de Lima. La catástrofe nacional fue definitoria para González Prada y su generación. La estela de pesimismo y revanchismo frustrado lo afectaron profundamente.

En un segundo aislamiento, don Manuel escribió piezas literarias. Durante cuatro años compuso un sainete satírico en versos octosilábicos, varias obras en prosa y otras piezas sarcásticas, además de una especie de poema cómico escenificado. Pero lo que más escribía con gusto eran letrillas, romances, epigramas, rondeles, sonetos, triolets y, sobre todo, balatas. También escribió varios ensayos de Ortometría.

\section{Presidencia del Círculo literario y de la Unión Nacional}

Cuando las tropas chilenas de ocupación abandonaron Lima en 1884, en virtud del Tratado de Ancón (1883), don Manuel puso fin a su aislamiento. Surgió de su segundo retiro, resuelto a predicar contra el desbarajuste moral y a enfrentarse a los responsables de la derrota. Con motivo de la muerte de Victor Hugo el 22 de mayo de 1885, don Manuel publicó en El Comercio una elegía en la que se identificó con sus objetivos vitales. A los pocos meses, para celebrar las Fiestas Patrias, don Manuel publicó en el mismo diario el artículo «Grau», que poco después fue reproducido como la pieza central del folleto $A$ los defensores de la patria, con trabajos de Ricardo Palma, José Antonio de Lavalle y otros escritores.

El conservador Club Literario de la capital peruana se convirtió en el Ateneo de Lima en 1885. Al año siguiente, Manuel dictó su conferencia requerida para su incorporación en esa institución. No obstante su creciente prestigio intelectual, el recién afiliado se desilusionó con la tradición literaria del Ateneo de Lima y, con un grupo de jóvenes, organizó el Círculo Literario como vehículo de una literatura basada en la ciencia y orientada así hacia el futuro. La nueva institución nació para «concurrir a la formación de una literatura eminentemente nacional ${ }^{1}$. En setiembre de 1887 el Círculo Literario lo eligió presidente para suceder a Luis Márquez, que se encontraba gravemente enfermo. $\mathrm{Al}$ asumir su puesto en el octubre siguiente, González Prada declaró en su discurso en el Palacio de la Exposición que consideraba al Círculo Literario como el «partido radical de nuestra literatura $»^{2}$.

En la celebración del 28 de julio de 1888, aniversario de la declaración de la independencia del Perú, en la que se recolectaron fondos para el rescate de las provincias cautivas Tacna y Arica, el ecuatoriano Miguel Urbina, con voz límpida, leyó en el Teatro Politeama de Lima la famosa disertación de González Prada «Discurso en el Politeama». Las felicitaciones por tan polémica pieza de oratoria, especialmente procedentes de pro-

1 Revista Social, nro. 72, 1 de noviembre de 1886.

2 Revista Social, nro. 120, 8 de noviembre de 1887. 
vincias, fueron difundidas por Abelardo Gamarra en La Integridad, para disgusto de los periódicos gubernamentales, que lo atacaban, condenaban y apoyaban su excomunión. El 30 de octubre de 1888, al cumplirse el año de la fundación del Círculo Literario, don Manuel aludió a don Ricardo Palma en su «Discurso en el Teatro Olimpo» cuando dijo: "Cultivamos una literatura de transición [...], ese monstruo engendrado por las falsificaciones agridulcetes de la historia y la caricatura microscópica de la novela [...]. Rompamos ese pacto infame y tácito de hablar a media voz».

En mayo de 1891 González Prada, Germán Leguía Martínez, Víctor Maúrtua, Luis Ulloa, Carlos Rey de Castro, el trujillano Wenceslao Cuadra y cuadros del Círculo Literario fundaron la Unión Nacional, cuya "Declaración de principios», redactada por don Manuel y publicada el 16 de mayo de 1891 en La Integridad, expresa objetivos reformistas para establecer un gobierno parlamentario dedicado a un programa de reformas sociales y medidas en defensa del indígena. Poco después, el nuevo partido político lo nombró su presidente.

\section{Estancia cultural en Europa (1891-1998)}

En el mismo 1891, los integrantes de la Unión Nacional se sorprendieron y se decepcionaron al recibir la noticia de que don Manuel y Adriana viajaban a Europa para satisfacer un viejo deseo de ampliar sus horizontes culturales y olvidar las pérdidas de sus dos primeros vástagos muertos al poco tiempo de nacer en Lima.

Una vez instalado en París, don Manuel asistió asiduamente a las clases de Ernest Renan y Louis-Nicolas Ménard en el Collège de France, y a las salas de lectura de la Biblioteca Nacional. Allá hizo pesquisas sobre métrica, rítmica. Además, leyó tanto las obras de antropólogos sociales (Le Bon, Gumplowicz y Tarde), como de los anarquistas Bakunin y Kropotkin. En La Sorbona, escuchó las charlas del egiptólogo Henri Maspero (18461916) y concurrió a charlas sobre literatura china. Se matriculó como alumno libre de esa venerable institución de alta cultura, alternando su asistencia con visitas a los museos y concurrencia a la Comédie Française y a la ópera.

El 16 de octubre de 1891 nació Alfredo, el hijo esperado. Pasados los primeros meses de engreír al niño entrañable, don Manuel reasumió la búsqueda cultural. A menudo asistía a la Biblioteca Nacional, al Museo del Louvre y a diversos auditorios donde se pronunciaban conferencias sobre el positivismo de Comte. En Mi Manuel, su viuda recuerda detalles de su vida parisina: estuvo presente en los sepelios de varias personalidades de renombre internacional: Renan, Maupassant, Leconte de Lisle y Louis Pasteur. En los funerales de Guy de Maupassant escuchó a Émile Zola su apología al amigo y correligionario de la escuela realista. Concurrió a representaciones de obras teatrales clásicas y se entusiasmó con las conferencias sobre positivismo. 
Para poder revisar todo el contenido de esta edición, visite nuestra tienda virtual.

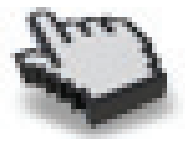

Veinte peruanos del siglo XX

Calderón - Victor Andrés Belaunde Manuel Gonzilez Prada - Francisco Garea Ear Vallejo - Honorio Delgado

José de la Riva-A guéro y Osma - Cesar Valcjo - José Carlos Mariátegui

losé Luis Bustamante y Rivero - Pedro G. Beitran - Jose Cartos Nari

Victor Raúl Haya de la Torre - Raúl Porras Barrencehca

Luis Aberto Sanchez - Jorge Basadre-jose Nana Anguedas Syszlo

Fernando Belaunde Terry - Luis Bedoya Rey - Mario Vargas Losa

Pedro Cateriano Bellido (Compilador)

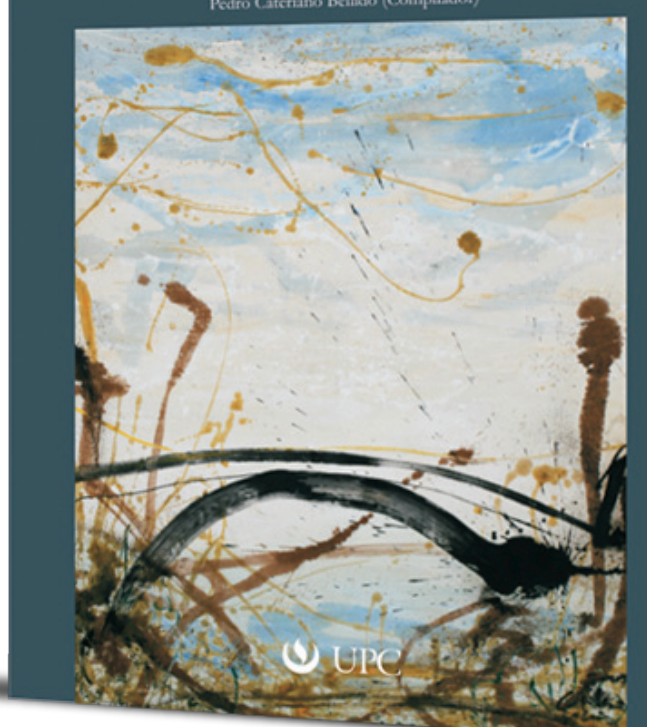

